\title{
Rheumatoid artrhitis treatment in Brazil: data from a large real-life multicenter study
}

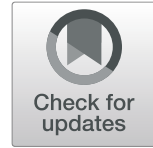

\author{
Ana Paula Monteiro Gomides ${ }^{1 *}$ (D), Cleandro Pires de Albuquerque ${ }^{1}$, Ana Beatriz Vargas Santos ${ }^{2}$, \\ Manoel Barros Bértolo ${ }^{3}$, Paulo Louzada Júnior ${ }^{4}$, Rina Dalva Neubarth Giorgi ${ }^{5}$, Sebastião Cezar Radominski ${ }^{6}$, \\ Maria Fernanda B. Resende Guimarães ${ }^{7}$, Karina Rossi Bonfiglioli ${ }^{8}$, Maria de Fátima Lobato da Cunha Sauma ${ }^{9}$, \\ Ivânio Alves Pereira ${ }^{10}$, Claiton Viegas Brenol ${ }^{11}$, Licia Maria Henrique da Mota ${ }^{1}$ and \\ Geraldo da Rocha Castelar Pinheiro²
}

\begin{abstract}
Background: Last decades witnessed great technological advances in rheumatoid arthritis (RA) management, but their implementation in clinical practice might prove difficult. Despite the efficacy demonstrated in controlled trials this information needs to be confirmed by real life data. This study assessed real-life treatment among RA patients.

Methods: REAL study included Brazilian RA patients from eleven centers. Interview and medical records were performed. Continuous variables were compared using Student's t or Mann-Whitney and categorical variables were assessed with chi-square or Fisher's exact tests.

Results: 1115 patients were included, women 89.5\%. Median age 56.6 years, disease duration 152.5 months; 78.7\% were rheumatoid fator positive; $55.2 \%$ had erosive disease; DAS28 (disease activity index-28 joints) $=3.5$, HAQ (health assessment questionnaire) $=0.875$. The median duration of symptoms until the start of first DMARD was 12 months. A total of 529 (47.2\%) patients used corticosteroids; 1022 (90.8\%) were on conventional synthetic (cs) DMARDs and 406 (36.1\%) on biological (b) DMARDs. Methotrexate (MTX) was the most frequent csDMARD: 748 (66.5\%) patients, followed by leflunomide (LFN), used by 381 (33.9\%) of patients. MTX was associated to LFN in 142 (12.6\%) patients. Only five (0.4\%) patients used triple therapy (MTX + hydroxychloroquine + sulfasalazine) or sulfasalazine in monotherapy.

Conclusions: Despite advances in therapeutic resources, roughly half RA patients failed achieve T2T goals and $55.2 \%$ developed erosive disease. The frequent use of corticosteroids and delay in initiating DMARDs were demonstrated. Issues concerning timely access to medical care are crucial for effective management.
\end{abstract}

Keywords: Rheumatoid arthritis, Drug therapy, Observational study, Latin America

\section{Background}

Rheumatoid arthritis (RA) is a chronic systemic autoimmune disease characterized by inflammatory involvement of the peripheral synovial joints [1]. Delays in diagnosis and initiation of disease-modifying antirheumatic drugs (DMARDs) can lead to joint destruction, deformities, and impairment of the patient's functional capacity and quality of life $[2,3]$.

In recent decades, there have been great advances in the management of RA, including new effective drugs

\footnotetext{
* Correspondence: anapmgomides@gmail.com

'Universidade de Brasília- UnB, Brasília, DF, Brazil

Full list of author information is available at the end of the article
}

and the advent of the "treat to target" (T2T) concept, based on frequent clinical assessment and adjustments as needed to attain sustained remission or low disease activity. Another important incorporated concept was that of a window of opportunity for most effective treatment. It is believed that early diagnosis and treatment with strict control of disease activity are associated with better outcomes and prognosis [4].

Current standards of care in RA incorporate these concepts and postulate a rational stepwise approach to the pharmacological treatment of the disease [5-7]. Although widely accepted by rheumatologists, T2T implementation and its actual benefits in day-to-day clinical 
practice are still not well established [8]. Unlike research settings, in real-life scenarios, constraints in access to healthcare resources, especially in less developed countries, might hinder the achievement of treatment goals and produce deviations from the expected standards of care [8].

The extent to which the recent advances in RA management are effectively being translated into better disease control in day-to-day practice can only be assessed through real-life epidemiological data. This study was aimed to assess the real-life patterns of treatment and their end results in terms of disease control, among RA patients in Brazil.

\section{Methods}

The REAL study assembled a cohort of RA patients attending eleven public health centers, from different regions of the country. From August, 2015 to April, 2016, each center enrolled approximately 100 consecutive patients [9]. Subjects should be 18 years of age or older, meet the American Rheumatism Association (1987) or American College of Rheumatology/European League Against Rheumatism (2010) classification criteria [10, 11], and have been followed up at their respective center for at least six months. Patients with comorbidities that could pose obstacle the planned assessment were excluded. Subjects were submitted to structured clinical interview with physical exam and thorough review of medical records, including laboratorial and imaging aspects. Data reported herein are cross-sectional, corresponding to the baseline assessment of participants, who would then be followed up for 12 months.

Disease activity was assessed using the Disease Activity Index-28 Joints (DAS28) and the Clinical Disease Activity Index (CDAI) [12]. Functional capacity (disability) was determined using the Health Assessment Questionnaire (HAQ) [13]. Health-related quality of life was assessed by the 12-Item Short-Form Health Survey (SF12) [14]. Erosive disease was characterized by the finding of erosions (breaking of the cortical bone) in at least three separate joints at any of the following sites: proximal interphalangeal, metacarpophalangeal, wrist, and metatarsophalangeal joints [15]. Rheumatoid factor and anti-cyclic citrullinated peptide antibody (anti-CCP) were defined as positive "low titer", when exceeding by less than 3 times the upper limit of normality, and as "high titer" when reaching 3 times the upper limit of normality or above.

Continuous variables were compared using Student's $t$ test or Mann-Whitney test, based on whether or not normality requirements were fulfilled. Categorical variables were compared using the chi-square test or Fisher's exact test [16]. A $p$ value $<0.05$ was deemed significant. Statistical analysis was performed using SAS
9.4 (SAS Institute Inc., Cary, North Carolina) and SPSS 20.0 (IBM Corp. Armok, NY). The study was approved by the local ethics committee and all participants granted informed consent.

\section{Results}

A total of 1115 patients $(89,5 \%$ female, median age of 56.6 years and median disease duration of 152.5 months) were included. An extended description of demographic characteristics of the REAL cohort has already been published [9] and are shown in Table 1. The Table 2 summarizes the patients' clinical characteristics.

By the time of assessment, 15 (1.3\%) patients were in clinical remission without any medication. Five hundred twenty-nine patients $(47.2 \%)$ were on corticosteroids, and $21(1.9 \%)$ took corticosteroids as their sole DMARD. The median (equivalent) dose of prednisone was $5 \mathrm{mg} /$ day (interquartile range, IQR $=1$ ). Among patients who were not on corticosteroids, 367 (61.6\%) reported their previous use. Corticosteroid users, compared to nonusers, showed higher mean scores (standard deviation, SD) on DAS28-ESR 3.9 (1.6) vs. 3.4 (1.4), DAS28-CRP 3.6 (1.5) vs. 3.1 (1.3), and HAQ 1.1 (0.8) vs. 0.8 (0.7), $p<$ 0.001 for all comparisons. Some features indicative of aggressive or refractory disease were associated with corticosteroid use (Table 3). There was no association between gender and corticosteroid use $(p=0.43)$.

Overall, 1022 patients (90.8\%) used conventional synthetic DMARDs (in monotherapy or combination); 406 (36.1\%) used a biological DMARD; 23 (5.7\%) of the biological DMARD users had it in monotherapy. Tofacitinib was then the only target-specific synthetic DMARD available in Brazil, taken by $9(0.8 \%)$ of cohort's patients

Table 1 Demographic data of patients with rheumatoid arthritis in the REAL study ${ }^{(9)}$

\begin{tabular}{lll}
\hline Demographic data & Absolute value or\% & $\mathrm{n}$ \\
\hline Years of study - median (min-max) & $8(0-20)$ & 1081 \\
Ethnicity & & 1115 \\
White & $56.8 \%$ & \\
Black & $10.9 \%$ & \\
Pardo & $31.3 \%$ & 1115 \\
Others & $1.0 \%$ & \\
Social Class & \\
A & & \\
B1 & $1.4 \%$ & \\
B2 & $3.5 \%$ & \\
C1 & $18.4 \%$ & \\
C2 & $27.4 \%$ & \\
D-E & $31.3 \%$ & \\
\hline
\end{tabular}

a Social classes based on average household income (Brazil criterion) A1: $R \$$ 20,888 B1: R \$ 9254 B2: R \$ 4852 C1 R \$ 2705 C2 R \$ 1625 D- E: R $\$ 768$ 
Table 2 RA patients' clinical characteristics in the REAL cohort

\begin{tabular}{|c|c|c|}
\hline Clinical Variable & Results & $\mathrm{N}^{\mathrm{a}}$ \\
\hline Disease duration ${ }^{\mathrm{b}}$, median (min-max) & $152.5(8-683)$ & 1115 \\
\hline Positive rheumatoid factor (\%) & 78.7 & 1105 \\
\hline Positive ACPA (\%) & 76.8 & 477 \\
\hline Time to first DMARD ${ }^{c}$, median (min-max) & $12(0-624)$ & 995 \\
\hline Erosive disease (\%) & 55.2 & 1105 \\
\hline DAS28-ESR, median (min-max) & $3.5(0.3-8.2)$ & 932 \\
\hline DAS28-CRP, median (min-max) & $3.7(1.0-8.1)$ & 944 \\
\hline CDAl, median (min-max) & $9(0-70)$ & 1122 \\
\hline $\mathrm{HAQ}$, median (min-max) & $0.875(0-3)$ & 1121 \\
\hline SF-12 physical component, median (min-max) & $36.1(17.5-55.9)$ & 1035 \\
\hline SF-12 mental component, median (min-max) & $46.9(14.3-72.0)$ & 1035 \\
\hline Remission (DAS28-ESR) & $26.2 \%$ & \\
\hline Low disease activity (DAS28-ESR) & $15.1 \%$ & \\
\hline Moderate disease activity (DAS28-ESR) & $41.8 \%$ & \\
\hline High disease activity (DAS28-ESR) & $16.9 \%$ & \\
\hline
\end{tabular}

a Numbers of patients assessed for each clinical variable. ${ }^{\mathrm{b}}$ Total disease duration in months. ${ }^{\mathrm{C}}$ Time-interval from first symptoms to first prescribed DMARD (in months). ACPA anti-citrullinated peptide antibody. DAS28 Disease Activity Score - 28 joints. ESR erythrocyte sedimentation rate. CDAl Clinical Disease Activity Index. HAQ Health Assessment Questionnaire. SF-12 12-Item Short-Form Health Survey

at that moment. The most prescribed therapeutic regimens of conventional synthetic DMARDs are presented in Table 4. The triple therapy with methotrexate (MTX) + sulfasalazine (SSZ) + hydroxichloroquine (HCQN) was used in only 5 patients $(0.4 \%)$; a similar figure was observed for sulfasalazine monotherapy (5 patients, $0.4 \%$ ). Table 5 reports the total frequencies of use for each synthetic and biological DMARDs (whether in combination or monotherapy).

Patients on methotrexate (MTX), whether in combination or not, compared to those not using the drug, had lower DAS28-CRP: mean (SD) score of 3.2 (1.3) for the MTX group and 3.4 (1.4) for the non-MTX group ( $p=$ 0.0043). There was also a trend toward lower DAS28ESR in MTX users [3.6 (1.5) vs. 3.7 (1.5), $p=0.056$ ].
MTX was less prescribed to patients with interstitial pneumonia, compared to those without this feature (OR 0.44; 95\%CI: $0.24-0.82 ; p=0.008)$. Leflunomide was less prescribed to individuals with subcutaneous nodules (OR 0.52; 95\%CI: 0.31-0.87; $p=0.011$ ). Patients on biological DMARDs, compared to those with only conventional synthetic drugs, showed higher scores on $\mathrm{HAQ}$, mean (SD): $1.03(0.76)$ vs. 0.90 (0.77), $p=0.007$. Some features of aggressive or refractory disease were also associated with biological DMARD prescription (Table 6).

\section{Discussion}

The Brazilian Ministry of Health provides free access to nearly all currently approved synthetic and biological DMARDs for the treatment of RA, and new technologies are continuously assessed for possible incorporation. To grant access to such costly drugs, the Ministry requires a medical prescription along with founded explanation of clinical motives, including data on disease activity scores. Moreover, the continuity of treatment depends on medical reports, which should account for current disease status on a regular 3-month basis. In other words, the Brazilian protocol for the management of RA does incorporate all relevant concepts and resources with proven efficacy in clinical trials. Nonetheless, concerns about extrapolating findings from controlled trials to larger uncontrolled scenarios, especially in less-favored economic backgrounds, are warranted $[17,18]$. The actual patterns of disease management in these population settings and their end results must be assessed through real-life data. The REAL study applied to that task.

The cohort was composed mainly of patients with long-term established RA (median of 152.5 months), with white race predominance (56.8\%) and a high prevalence of females $(89.5 \%)$. The female prevalence herein was similar to that in GLADAR, a multicenter study conducted in 14 Latin American countries, but higher than expected in North American and European populations [19]. The white race predominance followed a characteristic of the Brazilian population [20].

Table 3 Rheumatoid arthritis features associated with corticosteroid use

\begin{tabular}{|c|c|c|}
\hline Clinical feature ${ }^{a}$ & $\mathrm{~N}(\%)^{\mathrm{b}}$ & Odds ratio for corticosteroid use $(95 \%$ Cl) \\
\hline Moderate or high disease activity ${ }^{\complement}$ (DAS28-ESR) & $543(58.7)$ & $1.50(1.15-1.96)$ \\
\hline Moderate or high disease activity ${ }^{\mathrm{C}}$ (DAS28-CRP) & $437(57.3)$ & $1.59(1.23-2.06)$ \\
\hline High-titer rheumatoid factor ${ }^{d}$ & $616(56.1)$ & $1.64(1.29-2.08)$ \\
\hline Positive anti-CCP & $368(76.8)$ & $2.27(1.48-3.51)$ \\
\hline Erosive disease $^{e}$ & $602(54.9)$ & $1.56(1.23-1.98)$ \\
\hline Anemia & $78(7.03)$ & $2.37(1.46-3.85)$ \\
\hline Subcutaneous nodules & $92(8,3)$ & $1.82(1.18-2.82)$ \\
\hline
\end{tabular}

${ }^{a}$ Groups of patients with and without each feature were compared (binary logistic regression); $p<0.05$ for all comparisons. ${ }^{b}$ Total numbers and percentage of patients with the clinical feature among all those assessed for that variable. ${ }^{\mathrm{C}}$ Defined as DAS28 score $>3.2^{\mathrm{d}}$ Defined as at least 3 times the upper limit of normality ${ }^{e}$ Defined as at least 3 erosions in some specified joints (see methodology) 
Table 4 Preferred therapeutic regimens of conventional synthetic disease-modifying antirheumatic drugs (DMARDs) in Brazil

\begin{tabular}{ll}
\hline Synthetic DMARD Regimen $^{\text {a }}$ & N (\%) \\
\hline Methotrexate monotherapy & $154(13.7)$ \\
Methotrexate + corticosteroid & $135(12.0)$ \\
Methotrexate + leflunomide & $95(8.4)$ \\
Methotrexate + leflunomide + corticosteroid & $55(4.9)$ \\
Leflunomide monotherapy & $52(4.6)$ \\
Methotrexate + antimalarial (hydroxichloroquine or chloroquine) & $31(2.8)$ \\
Leflunomide + corticosteroid & $30(2.7)$ \\
Antimalarial (hydroxichloroquine or chloroquine monotherapy) & $17(1.5)$ \\
Other & $140(12.4)$ \\
\hline
\end{tabular}

${ }^{a}$ NSAIDs allowed for pain relief on an as-needed basis. ${ }^{b}$ All other regimens of conventional synthetic DMARD whether in monotherapy or combination (none exceeding $1.5 \%$ of prescriptions individually)

A high prevalence of rheumatoid factor was observed (78.7\%), similar to that in other Latin American and Brazilian studies. This feature has been associated with more aggressive disease, worse prognosis and possibly extra-articular manifestations [19, 21]. A high positivity rate for anti-CCP (76.8\%) was also found. Roughly, half of the patients failed to achieve the T2T goals of remission or low disease activity (as assessed by DAS28-ESR), exhibiting moderate or high disease activity instead. A similar proportion of patients had developed erosive disease. HAQ and SF-12 scores evidenced a noticeable impairment of health status and health-related quality of life in the cohort [22].

A high use of corticosteroids was identified (47.2\%), associated with some features of more aggressive disease, that is, higher disability (HAQ) and disease activity (DAS28) scores, high-titer rheumatoid factor, positivity to anti-CCP, erosive disease, anemia, and subcutaneous nodules. Even greater corticosteroid use (up to 66\%) was shown in Latin America by the GLADAR study [19].

Table 5 Total frequencies of conventional synthetic and biological DMARDs in the REAL cohort

\begin{tabular}{ll}
\hline DMARD & $\mathrm{N}(\%)$ \\
\hline Methotrexate & $748(66.5)$ \\
Leflunomide & $381(33.9)$ \\
Hydroxychloroquine & $120(10.7)$ \\
Sulfasalazine & $55(4.9)$ \\
Abatacept & $73(6.5)$ \\
Etanercept & $66(5.9)$ \\
Tocilizumab & $60(5.3)$ \\
Adalimumab & $54(4.8)$ \\
Infliximab & $50(4.4)$ \\
Rituximab & $49(4.4)$ \\
Golimumab & $37(3.3)$ \\
Certolizumab & $17(1.5)$ \\
\hline
\end{tabular}

However, GLADAR assessed patients with early RA, when corticosteroids are most used, while our cohort was composed mainly of established RA, when corticosteroids should be used only transiently for control of flares.

A selection bias toward more aggressive or refractory disease in tertiary healthcare centers might partially account for this high corticosteroid use, as well as for the high proportions of patients not achieving T2T goals and developing erosive disease. Nonetheless, issues related to timely access to medical care might also be playing a role in this scenario, ultimately determining delays in proper diagnosis and treatment and consequent loss of the window of opportunity for best results. In fact, the median delay from first symptoms to first prescribed DMARD in the cohort was 12 months, noticeably above the generally accepted width of (the first) 3 to 6 months of disease for initiating treatment, in order to attain the best possible results [23].

Methotrexate was the most widely used DMARD in Brazil (in $66.5 \%$ of patients), whether in monotherapy or in combinations. The MTX-containing regimens described herein are similar to those reported in other studies [15, 24]. MTX users showed lower clinical disease activity (as assessed by DAS28-ESR) than nonusers. Rheumatologists were less prone to prescribe MTX to patients with interstitial pneumonia, possibly because of concerns about interstitial lung disease progression or MTX-associated pneumonitis, even though this issue is still controversial [25].

Leflunomide was the second most commonly used DMARD (33.9\% of patients) in our cohort, a much larger number than in GLADAR (4\%) [19]. Brazilian rheumatologists plainly prefered leflunomide to sulfasalazine (used in only $4.9 \%$ of patients), two drugs deemed as comparable in efficacy [26]. It's our clinical impression, and based on these numbers, it might also be the case with other Brazilian rheumatologists, that leflunomide seems advantageous over sulfasalazine in 
Table 6 Clinical features associated with biological DMARD use

\begin{tabular}{|c|c|c|}
\hline Clinical feature $^{a}$ & $\mathrm{~N}(\%)^{\mathrm{b}}$ & Odds ratio for bDMARD use $(95 \% \mathrm{Cl})$ \\
\hline High-titer rheumatoid factor ${ }^{c}$ & $616(56.1)$ & $1.45(1.12-1.86)$ \\
\hline Interstitial pneumonia $^{d}$ & $42(3.8)$ & $1.84(0.99-3.42)$ \\
\hline Erosive disease $\mathrm{e}^{\mathrm{a}}$ & $602(54.9)$ & $1.47(1.14-1.89)$ \\
\hline Cutaneous vasculitis & $13(1.2)$ & $4.12(1.26-13.47)$ \\
\hline Subcutaneous nodules & $92(8.3)$ & $1.73(1.13-2.66)$ \\
\hline
\end{tabular}

${ }^{a}$ Groups of patients with and without each feature were compared (binary logistic regression); $p<0.05$ for all comparisons. ${ }^{b}$ Total numbers and percentage of patients with the clinical feature among all those assessed for that condition. ${ }^{c}$ Defined as at least 3 times the upper limit of normality ${ }^{d}$ Defined by findings suggestive of interstitial X-ray disease: ground-glass opacities, fibrosis compatible lesions (honeycombing, traction bronchiectasis / bronchiolectasis, irregular interlobular septal thickening, and irregular interfaces) ${ }^{e}$ Defined as at least 3 erosions in some specified joints (see methodology)

our population (yet to be verified in a clinical trial). Even hydroxychloroquine $(10.7 \%)$, currently recommended for RA treatment in only special situations, was favored in comparison to sulfasalazine. The reasons underlying this relative disregard for sulfasalazine and clear preference for leflunomide among Brazilian rheumatologists might be worth studying, from a pharmacogenetic point of view.

Moreover, a significant proportion of patients (13.3\%) were using the MTX + leflunomide combination, with or without corticosteroids. Although the efficacy of this regimen has been demonstrated, it is rarely used in other countries due to concerns about adverse effects, especially hepatotoxicity [27-29]. Nonetheless, the SMILE study $(n=2975)$ found the combination of MTX + leflunomide to be well tolerated, with adverse events comparable to those of monotherapy with each drug [30]. Given its relative low cost, it is an alternative to be considered before starting a biological therapy, especially in locations with scarce resources.

The use of triple therapy with MTX + hydroxychloroquine + sulfasalazine was extremely low $(0.4 \%$ of patients) in our cohort. Infrequent use of this combination therapy was also reported in the USA [31]. However, this is a low-cost regimen, with efficacy comparable to biological DMARDs in some scenarios. In low-income countries, this option should be considered, before starting a biological DMARD, particularly for patients without poor prognostic factors [32, 33]. Brazilian rheumatologists should probably be heeding this therapeutic regimen more carefully.

Biological DMARD use (36.1\%) in our cohort was more frequent than in studies of early RA conducted in Brazil and Latin America [17, 19, 21]. Patients treated early in the course of disease are supposed to respond better and to require less of the more advanced resources, such as biological DMARDs, in the stepwise approach to RA management [23]. Biological DMARD use was associated with some features of disease aggressiveness, i.e., higher disability (HAQ) scores, high-titer rheumatoid factor, erosive disease, pulmonary fibrosis, subcutaneous nodules and cutaneous vasculitis.
The nature of the data gathered by the REAL study, i.e., reflecting real-life clinical patterns of RA management in Brazil, warrants caution in extrapolating these findings to other population settings. Nevertheless, the study describes for the first time with such a scale the dynamics of real-life treatment of RA in this region, and might serve as a proxy to a better understanding of RA treatment specificities in developing countries, especially in Latin America.

\section{Conclusions}

In summary, we demonstrated herein that, in real-life, despite granted access to all advanced pharmacological resources for RA management in Brazil, roughly half of the patients did not achieve T2T goals and developed erosive disease. A high use of corticosteroids was observed in association with signs of aggressive or refractory disease. There was a clear preference for leflunomide over sulfasalazine among Brazilian rheumatologists for the treatment of RA. Triple therapy with MTX + sulfasalazine + hydroxichloroquine was seldom used. Methotrexate plus leflunomide combined therapy was common. Issues concerning timely access to healthcare resources, thus avoiding delays in initiating a DMARD within the first months of disease, might be crucial to effective RA management.

\section{Abbreviations}

Anti-CCP: Anti-cyclic citrullinated peptide antibody; CDAl: Clinical Disease Activity Index; DAS28: Disease Activity Index-28 Joints; DMARD: Diseasemodifying anti-rheumatic drugs; HAQ: Health Assessment Questionnaire; SF 12: 12-Item Short-Form Health Survey

\section{Acknowledgments}

We thank the Brazilian Society of Rheumatology and the Rheumatology team of the University Hospital of Brasília - HUB-UnB for support of this project.

\section{Authors' contributions}

All authors made substantial contributions to the acquisition of data, have been involved in drafting the manuscript or revising it critically for important intellectual content, gave final approval of the version to be published and have participated sufficiently in the work to take public responsibility for appropriate portions of the content; and agreed to be accountable for all aspects of the work in ensuring that questions related to the accuracy or integrity of any part of the work are appropriately investigated and resolved. In addition, GRCP, ABVS and LMHM also made substantial contributions to 
conception and design of the study. The authors read and approved the final manuscript.

\section{Funding}

This work was supported by the Brazilian Society of Rheumatology (BSR). For this project, BSR received specific grant support from the following companies: Bristol-Myers Squibb Farmacêutica Ltda; Eli Lilly do Brasil Ltda; Janssen-Cilag Farmacêuticos Ltda; Laboratórios Pfizer Ltda; Produtos Roche Químicos e Farmacêuticos S.A. and UCB Biopharma Ltda. The funding body or the companies had no role in the design of the study and collection, analysis, and interpretation of data and in writing the manuscript.

\section{Availability of data and materials}

The datasets used and/or analysed during the current study are available from the corresponding author on reasonable request.

\section{Ethics approval and consent to participate}

This study was approved by the National Commission of Ethics in Research (CONEP - Comissão Nacional de Ética em Pesquisa) - Ministry of Health. The coordinating center was the University of the State of Rio de Janeiro, and the approval number was 45781015.8.1001.5259. Each of the centers also obtained approval from the respective Institutional Review Boards. All patients signed the informed consent form.

\section{Consent for publication}

Not applicable.

\section{Competing interests}

APMG: Has received personal support and consulting fees from Pfizer. GRCP: Has received consulting fees from AbbVie, Bristol-Myers Squibb, Eli Lilly, Glaxosmithkline, Janssen, Pfizer, Sanofi Genzyme and Roche; ABVS: Has received supporting for international medical events from AbbVie and Janssen; CPA: Has received personal fees and/or non-financial support from Pfizer, AbbVie, AstraZeneca, Janssen, Bristol-Myers Squibb, Roche, Novartis and UCB, outside the submitted work; MBB: Has participated in clinical and/or experimental studies related to this work and sponsored by Roche; has delivered speeches at events related to this work and sponsored by AbbVie and Pfizer; PLJ: Has received supporting for internationals congresses from Bristol-Myers Squibb, UCB and consulting fees from Pfizer; RDNG: Has received consulting fees, speaking fees and supporting for internationals congresses from Roche, Pfizer, Bristol-Myers Squibb, UCB, Eli-Lilly, AbbVie, Abbott and EMS; SCR: Has received consulting and speaking fees from Abbvie, Janssen, Pfizer, Roche and UCB; MFBRG: Has received speaking fees and supporting for congresses from AbbVie, Bristol-Myers Squibb, Janssen, Novartis, Pfizer, Roche and UCB; KRB: Has received speaking fees and supporting for international congresses from Roche, Pfizer, Bristol-Myers Squibb, Abbvie and Janssen; MFLCS: No financial disclosures; CVB: Has participated in clinical and/or experimental studies related to this work and sponsored by AbbVie, BMS, Janssen, Pfizer and Roche: has received personal or institutional support from AbbVie, BMS, Janssen, Pfizer and Roche; has delivered speeches at events related to this work and sponsored by AbbVie, Janssen, Pfizer and Roche; IAP: Has received consulting fees, speaking fees and supporting for internationals congresses from Roche, Pfizer, UCB Pharma, Eli-Lilly, Abbvie and Janssen; ESFC: No financial disclosures; LMHM: Has received personal or institutional support from AbbVie, Janssen, Pfizer and Roche; has delivered speeches at events related to this work and sponsored by AbbVie, Janssen, Pfizer, Roche and UCB.

\section{Author details}

${ }^{1}$ Universidade de Brasília- UnB, Brasília, DF, Brazil. ${ }^{2}$ Universidade do Estado do Rio de Janeiro, Rio de Janeiro, RJ, Brazil. ${ }^{3}$ Universidade Estadual de Campinas, Campinas, SP, Brazil. ${ }^{4}$ Faculdade de Medicina da Universidade de Ribeirao Preto, Universidade de Sao Paulo, Ribeirão Preto, SP, Brazil. ${ }^{5}$ Instituto de Assistência Médica ao Servidor Público Estadual, Hospital do Servidor Público Estadual de São Paulo, São Paulo, SP, Brazil. 'Universidade Federal do Paraná, Curitiba, PR, Brazil. ${ }^{7}$ Universidade Federal de Minas Gerais, Belo Horizonte, MG, Brazil. ${ }^{8}$ Universidade de São Paulo, São Paulo, SP, Brazil. ${ }^{9}$ Universidade Federal do Pará, Belém, PA, Brazil. ${ }^{10}$ Universidade Federal de Santa Catarina, Florianópolis, SC, Brazil. ${ }^{11}$ Universidade Federal do Rio Grande do Sul, Porto Alegre, RS, Brazil.
Received: 10 July 2019 Accepted: 17 February 2020

Published online: 27 February 2020

\section{References}

1. Majithia $V$, Geraci SA. Rheumatoid arthritis: diagnosis and management. Am Med. 2007;120:936-9.

2. Van der Horst-Bruinsma IE, Speyer I, Visser H, Breedvelt FC, Hazes GM. Diagnosis and course of early-onset arthritis: results of a special early arthritis clinic compared to routine patient care. Br J Rheumatol. 1998;37: 1084-8.

3. Nell VPK, Machold KP, Eberl G, Stamm TA, Uffmann M, Smolen JS. Benefit of very early referral and very early therapy with disease-modifying antirheumatic drugs in patients with early rheumatoid arthritis. Rheumatol. 2004:43:906-14.

4. Smolen JS, Aletaha D, Bijlsma JW, Breedveld FC, Boumpas D, Burmester G. Treating rheumatoid arthritis to target: recommendations of an international task force. Ann Rheum Dis. 2010;69:631-7.

5. Mota LMH, Kakehasi AM, Gomides APM, Duarte ALBP, Cruz BA, Brenol CV et al. 2017 recommendations of the Brazilian Society of Rheumatology for the pharmacological treatment of rheumatoid arthritis. Adv Rheumatol 2018; 58:2. https://doi.org/https://doi.org/10.1186/s42358-018-0005-0.

6. Smolen JS, Landewé R, Bijlsma J, Burmester G, Chatzidionysiou K, Dougados $M$, et al. EULAR recommendations for the management of rheumatoid arthritis with synthetic and biological disease-modifying antirheumatic drugs: 2016 update. Ann Rheum Dis. 2017;76:960-77.

7. Singh JA, Saag KG, Bridges SL, Akl EA, Bannuru RR, Sullivan MC, et al. 2015 American College of Rheumatology Guideline for the treatment of rheumatoid arthritis. Arthritis Care Res. 2016;68:1-25.

8. Solomon DH, Bitton A, Katz JN, Radner H, Brown E, Fraenkel L. Treat to target in rheumatoid arthritis: fact, fiction or hypothesis? Arthritis Rheumatol. 2014;66:775-82.

9. Castelar-Pinheiro $G R$, Vargas-Santos $A B$, Albuquerque $C P$, Bértolo MB, Júnior PL, Giorgi RDN et al The REAL study: a nationwide prospective study of rheumatoid arthritis in Brazil. Adv Rheumatol 2018. https://doi.org/https:// doi.org/10.1186/s42358-018-0017-9.

10. Arnett FC, Edworthy SM, Bloch DA, McShane DJ, Fries JF, Cooper NS, et al. The American rheumatism association 1987 revised criteria for the classification of rheumatoid arthritis. ArthritisRheum. 1998;31:315-24.

11. Aletaha D, Neogi T, Silman AJ, Funovits J, Felson DT, Bingham CO 3rd, et al. 2010 rheumatoid arthritis classification criteria: an American College of Rheumatology/European league against rheumatism collaborative initiative. Arthritis Rheum. 2010;62:2569-81.

12. Gaujoux-Viala C, Mouterde G, Baillet A, Claudepierre P, Fautrel B, Le Loët X, et al. Evaluating disease activity in rheumatoid arthritis: which composite index is best? A systematic literature analysis of studies comparing the psychometric properties of the DAS, DAS28, SDAI and CDAI. Joint Bone Spine. 2012;79:149-55.

13. Fries JF, Spitz $P$, Kraines RG, Holman HR. Measurement of patient outcome in arthritis. Arthritis Rheum. 1980;23:137-45.

14. Ware J Jr, Kosinski M, Keller SD. A 12-item short-form health survey: construction of scales and preliminary tests of reliability and validity. Med Care. 1996 Mar;34(3):220-33.

15. Van der Heijde D, Van der Helm-van MAH, Aletaha D, Bingham CO, Burmester GR, et al. EULAR definition of erosive disease in light of the 2010 ACR/EULAR rheumatoid arthritis classification criteria. Ann Rheum Dis. 2013; 72(4):479-81.

16. Agresti A. An introduction to categorical data analysis. 2nd ed. New York: Wiley; 2007

17. Mota LM, Brenol CV, Palominos P, Pinheiro GR. Rheumatoid arthritis in Latin America: the importance of an early diagnosis. Clin Rheumatol. 2015; 34(Suppl 1):S29-44.

18. Saturni S, Bellini F, Braido F, Paggiaro P, Sanduzzi A, Scichilone N, et al Randomized Controlled Trials and real life studies. Approaches and methodologies: a clinical point of view. Pulm Pharmacol Ther. 2014;27(2): 129-38.

19. Cardiel MH, Pons-Estel BA, Sacnun MP, Wojdyla D, Saurit V, Marcos JC, et al. Treatment of early rheumatoid arthritis in a multinational inception cohort of Latin American patients: the GLADAR experience. J Clin Rheumatol. 2012; 18(7):327-35.

20. Instituto Brasileiro de Geografia e Estatistica - IBGE ; População; 2010. Available from: www.ibge.gov.br. Accessed 23 Mar 2018. 
21. Mota LMH, Laurindo IMM, Neto LLS. Características demográficas e clínicas de uma coorte de pacientes com artrite reumatoide inicial. Rev Bras Reumatol. 2010;50(3):235-48.

22. Linde L, Sorensen J, Ostergaard M, Horslev-Petersen K, Rasmussen C, Jensen DV, et al. What factors influence the health status of patients with rheumatoid arthritis measured by the SF-12v2 health survey and the health assessment questionnaire? J Rheumatol. 2009;36(10):2183-9.

23. Raza K, Filer A. The therapeutic window of opportunity in rheumatoid arthritis: does it ever close? Ann Rheum Dis. 2015;74(5):793-4.

24. Swierkot J, Szechiński J. Methotrexate in rheumatoid arthritis. Pharmacol Rep. 2006;58(4):473-92.

25. Conway R, Low C, Coughlan RJ, O'Donnell MJ, Carey JJ. Methotrexate and lung disease in rheumatoid arthritis: a meta-analysis of randomized controlled trials. Arthritis Rheumatol. 2014;66(4):803-12.

26. Scott DL, Smolen JS, Kalden JR, van de Putte LB, Larsen A, Kvien TK, et al. Treatment of active rheumatoid arthritis with leflunomide: two year follow up of a double blind, placebo controlled trial versus sulfasalazine. Ann Rheum Dis. 2001;60(10):913-23.

27. Kremer JM, Genovese MC, Cannon GW, Caldwell JR, Cush JJ, Furst DE, et al. Concomitant leflunomide therapy in patients with active rheumatoid arthritis despite stable doses of methotrexate. A randomized, double-blind, placebo-controlled trial. Ann Intern Med. 2002:137(9):726-33.

28. Roon ENV, Tim LTA, Houtman NM, Spoelstra P, Brouwers JR. Leflunomide for the treatment of rheumatoid arthritis in clinical practice. Drug Saf. 2004; 27(5):345-52.

29. Administration USFDA. Drug Safety Communication: new boxed warning for severe liver injury with arthritis drug Arava (leflunomide). https://www. fda.gov/drugs/drug-safety-and-availability. Accessed 15 Mar 2018.

30. Bird P, Griffiths H, Tymms K, Nicholls D, Roberts L, Arnold M, et al. The SMILE study - safety of methotrexate in combination with leflunomide in rheumatoid arthritis. J Rheumatol. 2013;40(3):228-35.

31. O'Dell JR. Triple therapy with methotrexate, sulfasalazine, and hydroxychloroquine in patients with rheumatoid arthritis. Rheum Dis Clin North. 1998;24(3):465-77.

32. Bansback N, Phibbs CS, Sun H, O'Dell JR, Brophy M, Keystone EC, et al. Triple therapy versus biologic therapy for active rheumatoid arthritis: a costeffectiveness analysis. Ann Intern Med. 2017;167(1):8-16.

33. Mary J, De Bandt M, Lukas C, Morel J, Combe B. Triple Oral therapy versus antitumor necrosis factor plus methotrexate (MTX) in patients with rheumatoid arthritis and inadequate response to MTX: a systematic literature review. JRheumatol. 2017:44(6):773-9.

\section{Publisher's Note}

Springer Nature remains neutral with regard to jurisdictional claims in published maps and institutional affiliations.

Ready to submit your research? Choose BMC and benefit from:

- fast, convenient online submission

- thorough peer review by experienced researchers in your field

- rapid publication on acceptance

- support for research data, including large and complex data types

- gold Open Access which fosters wider collaboration and increased citations

- maximum visibility for your research: over $100 \mathrm{M}$ website views per year

At $\mathrm{BMC}$, research is always in progress.

Learn more biomedcentral.com/submissions 